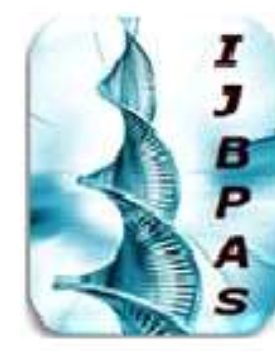

International Journal of Biology, Pharmacy and Allied Seiences (IJBPAS)

'A Bridge Betusen Caboratory and Q quder'

WwW.iibpas,com

FORMULATION AND EVALUATION OF NIOSOMAL BASED HERBAL SUNSCREEN SPRAY

\title{
CHANDIRANI $\mathrm{P}^{1^{*}}$, SUSMITHA $\mathrm{P}^{1^{*}}$, BAJI SK ${ }^{1^{*}}, \operatorname{SRAVANI~} \mathrm{T}^{1^{*}}$, JYOTHIKA VL $^{1^{*}}$, PALLAVI V ${ }^{2}$ AND RAMARAO $\mathbf{N}^{3}$
}

1: UG Scholar, Chalapathi Institute of Pharmaceutical Sciences

2: Assistant Professor, Department of Pharmaceutics, Chalapathi Institute of Pharmaceutical Sciences

3: Principal, Chalapathi Institute of Pharmaceutical Sciences

*Corresponding Author: P. Chandirani: E Mail: chandirani578@gmail.com; Tel: $+917993442137$

Received 20 ${ }^{\text {th }}$ March 2020; Revised $21^{\text {st }}$ April 2020; Accepted $15^{\text {th }}$ May 2020; Available online $1^{\text {st }}$ Nov. 2020 https://doi.org/10.31032/IJBPAS/2020/9.11.5244

\section{ABSTRACT}

Background: In the current paradigm, herbal remedies are more appropriate than synthetic ones due to their protection and less harmful impacts. The present research work has been undertaken with the aim to formulate and evaluate niosomal based herbal sunscreen spray.

Materials and methods: Essential oils (carrot seed oil, blue berry seed oil) having good SPF. Aloe vera (Aloe barbadensis Mill. belonging to the family Asphodelaceae), Cholesterol, Tween80, Alcohol, Glycerine, Water. Niosomes were prepared by coacervation method.

Results: It has been identified that carrot seed oil, blue berry seed oil have good SPFs. The combination of both the essential oils is having SPF higher than the individual formulations. 3 formulations are made F1, F2, F3. Carrot seed oil was incorporated as a UV protecting agent in F1 and SPF was found to be 27.78; blue berry seed oil was incorporated as UV protectant in F2 and SPF was found to be 21.65 and F3 is the combination of both carrot seed oil and blue berry seed oil where the SPF was found to be 28.90 . 
Conclusion: Results have shown that F3 is having high SPF than F1 and F2. Thus it has high UV protection capacity.

Keywords: Niosomal, Carrot seed oil, Blue berry seed oil, Asphodelaceae, Coacervation, SPF (Sun protection factor)

\section{INTRODUCTION}

Sunscreens: Sunscreens are the substances that protect the skin from UV radiation, helps to prevent the development of wrinkles, darkspots and sagging skin. Modern sun screens provide excellent and robust protection against UVA and UVB while avoiding water and sweat wash-offs. Aerosol sprays are of great demand because they are easy to use and fairly quick to apply [1].

\section{Types of UV- Radiation [2]}

UV-A Radiation: This ranges from 320 to $400 \mathrm{~nm}$. UV-A radiation is primarily responsible of tanning or darkening of the skin.

UV-B radiation: Radiation ranges from 280 to $320 \mathrm{~nm}$. It is known as burning rays because it causes sunburn 1000 times more than UV-A.

UV-C radiation: The radiation ranges from 200 to $280 \mathrm{~nm}$. UV-C radiation is less powerful and harmful.

\section{Protection:}

Sun protection choices can be very common, but suntan screens are the most preferred and popular mode of sun protection due to numerous social factors such as ease of application and greater safety effects. Most animals (the elephant uses mud as a sun cover) use sunlight. Sun protection clothing, sun glasses, hats, umbrellas, shade and potential avoidance of sun light [3].

SPF is measured as ratio of amount of UV radiation required to burn the protected skin (with sunscreen) to that required to burn the same unprotected skin (without sunscreen), all other factors being constant.

SPF = Minimal erythema dose of protected skin Minimal erythema dose of unprotected skin Mansur mathematical equation

$$
\begin{gathered}
\mathrm{SPF}=\mathrm{CF} \sum{ }_{290}{ }^{320} \operatorname{EE}(\lambda) \times \mathrm{I}(\lambda) \operatorname{Abs}(\mathrm{c}) \\
\text { Where, } \\
\mathrm{CF}=\text { Correction factor }
\end{gathered}
$$

$\mathrm{EE}[\lambda]=$ Erythmagenic effect of radiation with wavelength

$\operatorname{Abs}[\lambda]=$ Spirit photometric absorbance values at wavelength EE values are constant

\section{Herbal sunscreen agents:}

These herbal sunscreen acts by either effectively scattering the incident light or they adsorb the erythemal portion of sun energy.

\section{Aloe vera gel:}

It is collected from the leaves of Aloe barbadensis belonging to the family Asphodelaceae. Aloe vera is widely used in 
cosmetics for its moisturizing action. It can block both UVA and UVB rays, so that it can maintain skin natural moisture balance. Aloe contains the enzyme bradykinase which stops sunburns and stimulate immune system. Acemannan is the main ingredient in aloe vera. It is a D-isomer of mucopolysaccaride which speeds up the repair phase and increase production of collagen and fibroblasts [4].

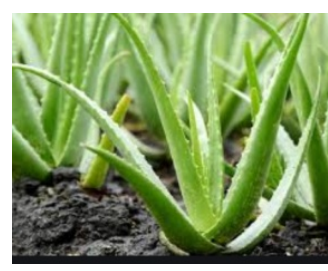

\section{Carrot seed oil:}

It is yellow to pale orange-brown in colour. It contains 3 flavones (luteolin, luteolin 3-Obeta-D-glucopyranoside, luteolin 4-O-betaD-pyranoside). These flavones are having high anti oxidant properties which are helpful in treatment of skin related problems and also protects skin from UV radiations [5].

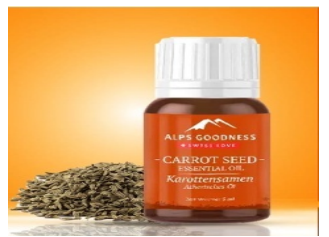

Blue berry seed oil: It is highly moisturizing with charecteristic aroma. It contains high concentration of alpha and gamma tocopherols (vitamin E), vitamin C, poly phenols, $83 \%$ omega-3 and omega-6 fatty acids, vitamin A. It is also useful in treatment of psoriasis and other skin conditions. It is a strong anti oxidant and also used for its healing and nourishing properties. Due to high vitamin A content it is suitable for oily and acneic skin types [6].

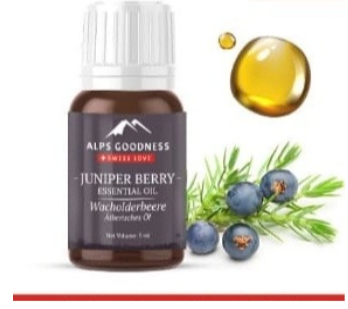

\section{MATERIALS and METHODS}

\section{Collection of materials:}

Aloe vera was collected from our college (Chalapathi Institute of Pharmaceutical Sciences) medicinal garden. Carrot seed oil and blue berry oil were procured from ALPS Goodness Pvt. Ltd. Cholesterol, Tween80, alcohol, Glycerine were procured from Thermo Electronus India Pvt. Ltd. Aloe vera used for the experimental work was authenticated in Acharya Nagarjuna University.

\section{Method of Preperation}

\section{Coacervation Method of Preperation of}

\section{Proniosomes}

Taken the required quantity of cholesterol into a clean and dry beaker. Placed the beaker on magnetic stirrer with moderate $\mathrm{rpm}$ and $30-35^{\circ} \mathrm{C}$. To this Tween 80 was added. Finally aloevera, essential oils and alcohol were incorporated. Stirred the above 
contents until all the ingredients were completely miscible and formed a single phase at $60-65^{\circ} \mathrm{C}$. Slowly added the aqueous phase and stirred to form a uniform dispersion.

Table 1: List of Ingredients

\begin{tabular}{|c|c|c|c|}
\hline S. No & NAME OF INGREDIENT & QUANTITY & PURPOSE \\
\hline 1. & Carrot seed oil & $5 \mathrm{ml}$ & Essential oil with SPF of 35-40 \\
\hline 2. & Blue berry oil & $5 \mathrm{ml}$ & Essential oil with SPF of 20 \\
\hline 3. & Aloe vera & $10 \mathrm{gms}$ & Skin Moisturizer \\
\hline 4. & Cholesterol & $5 \mathrm{gms}$ & Lipid phase for niosomes \\
\hline 5. & Tween 80 & $10 \mathrm{ml}$ & Non ionic surfactant \\
\hline 6. & Alcohol & $10 \mathrm{ml}$ & Penetration enhancer \\
\hline 7. & Glycerine & $10 \mathrm{ml}$ & Aqueous phase \\
\hline 8. & Water & $\mathrm{qs}$ & Aqueous phase \\
\hline
\end{tabular}

Table 2: Composition of Formulation

\begin{tabular}{|c|c|c|c|c|}
\hline S. No & NAME OF INGREDIENT & F1 & F2 & F3 \\
\hline 1. & Carrot seed oil & $1 \mathrm{ml}$ & - & $1 \mathrm{ml}$ \\
\hline 2. & Blue berry oil & - & $1 \mathrm{ml}$ & $1 \mathrm{ml}$ \\
\hline 3. & Aloe vera & $10 \mathrm{gms}$ & $10 \mathrm{gms}$ & $\mathbf{1 0 g m s}$ \\
\hline 4. & Cholesterol & $0.25 \mathrm{gms}$ & $\mathbf{0 . 2 5} \mathrm{gms}$ & $\mathbf{0 . 2 5} \mathrm{gms}$ \\
\hline 5. & Tween 80 & $1.5 \mathrm{ml}$ & $1.5 \mathrm{ml}$ & $1.5 \mathrm{ml}$ \\
\hline 6. & Alcohol & $10 \mathrm{ml}$ & $10 \mathrm{ml}$ & $10 \mathrm{ml}$ \\
\hline 7. & Glycerine & $1 \mathrm{ml}$ & $1 \mathrm{ml}$ & $1 \mathrm{ml}$ \\
\hline 8. & Water & $q \mathrm{q}$ & $q \mathrm{~s}$ & $\mathbf{q s}$ \\
\hline
\end{tabular}

\section{Evaluation Parameters}

\section{Physical parameters:}

Appearance, colour, and solubility were determined.

By using standard techniques and methods the physical parameters of herbal sunscreen formulations like colour, odour, spreadability, $\mathrm{pH}$, specific gravity $\left(25^{\circ} \mathrm{C}\right)$ and limit test for lead were determined. The viscosity of sunscreen was measured at 10$100 \mathrm{rpm}$ at $25^{\circ} \mathrm{C}$ with Brookfield viscometer. Stability of sunscreen was determined by centrifugation at 3500-13500 rpm for $10 \mathrm{~min}$ interval and observed for phase separation. A sensitivity study was done by patch test to ensure that sunscreen is free from adverse effects [7].

\section{Subjective Properties:}

Consistency, feel on application and irritation parameters were determined.

\section{Rancidity:}

This test was performed by using the Phloroglucinol solution. The rancidity is due to the oxidation of the fats and oils; during oxidation free fatty acids were liberated. These free fatty acids react with the Phloroglucinol solution and gives pink colour. This indicates the rancidity of the 
product. $10 \mathrm{ml}$ of the preparation was taken then added $10 \mathrm{ml}$ of concentrated hydrochloric acid and $10 \mathrm{ml}$ of Phloroglucinol solution and shaken for one minute. The material shall be taken to have passed the test if no pink colour developed [8-12].

\section{Particle size analysis:}

Particle size of niosomes formed was determined with the help of particle size analyser.

Percentage of nanoparticles formed and the range of particle size was obtained in the form of a graph.

Initially, the sample was transferred to a cuvette and placed in a particle size analyser, final results obtained in the form of graph was collected and evaluated.

\section{Sun Protection Factor determination [8]}

SPF of formulated creams, marketed sunscreen products and synthetic sunscreen agents were calculated by the application of equation:

\section{Sample Preparation}

Weighed $1.0 \mathrm{~g}$ of both the samples and added into $100 \mathrm{ml}$ volumetric flask, diluted with ethanol and ultrasonicated for $5 \mathrm{~min}$. Filtered using cotton and then rejected first $10 \mathrm{ml}$. Into a $50 \mathrm{ml}$ volumetric flask an aliquot of $5 \mathrm{ml}$ was transferred and diluted with ethanol. To the $25 \mathrm{ml}$ volumetric flask an aliquot $5 \mathrm{ml}$ was transferred and diluted with ethanol. Measured the absorbance values of each aliquot from $290-320 \mathrm{~nm}$ at $5 \mathrm{~nm}$ interval taking ethanol as a blank. The absorbance values were taken thrice and at each point determinations were made followed by application of Mansur equation. Mansur et al (1986) [13-17] developed a mathematical equation

$$
\mathrm{SPF}=\mathrm{CF} \sum 29{ }^{320} \mathrm{EE}(\lambda) \times \mathrm{I}(\lambda) \mathrm{Abs}(\mathrm{c})
$$

Where,

$\mathrm{CF}=$ correction factor

$\operatorname{EE}[\lambda]=$ Erythmagenic effect of radiation with wavelength

$\operatorname{Abs}[\lambda]=$ spirit photometric absorbance values at wavelength

\section{EE values are constant}

The aliquot prepared were scanned between 290-320 $\mathrm{nm}$ and the obtained absorbance values were multiplied with the respective EE $(\lambda)$ and I $(\lambda)$ values. Then, their summation was taken and multiplied with the correction factor (10) [18-22].

\section{RESULTS AND DISCUSSION:}

Effectiveness of a sunscreen was determined by using SPF. An effective sunscreen should have wide range of absorbance from 290$400 \mathrm{~nm}$ to prevent sunburn and skin damage. Evaluation of sunscreen formulation for a long time was through in- vivo test using human volunteers but it is time consuming 
and leads to grade of variability. But, during production and development the SPF test is useful for scanning. By applying mathematical equation the herbal sunscreen containing carrot seed oil and blueberry seed oil were evaluated.

During handling and storage of cosmetic formulation

- The prime parameters which effect formulations acceptability are physicochemical characters.

- Phase separation was not observed by performing stability studies using centrifugation. This proves the stability of formulation at high stress conditions.
- By using UV spectrophotometric method, the SPF values were obtained and observed high absorbance values at $290-320 \mathrm{~nm}$. The SPF values of carrot seed, blue berry oil and combination of both oils in sunscreen spray were $27.78,21.65$ and 28.90 respectively.

\section{Particle size analysis:}

Particle size of niosomes was analysed by particle size analyser.

It was found that almost $30 \%$ of particles in the sample were of nano size.

Average particle size of the formulation was found to be 0.5 microns.

Table 3: Physical Properties of Herbal Drugs

\begin{tabular}{|c|c|c|c|c|}
\hline \multirow[b]{2}{*}{ S. NO } & \multirow[b]{2}{*}{ parameters } & \multicolumn{3}{|c|}{ observations } \\
\hline & & F1 & F2 & F3 \\
\hline 1 & Colour & Yellowish to brown & light greenish yellow & Yellowish brown \\
\hline 2 & Odour & characteristic & characteristic & characteristic \\
\hline 3 & Specific gravity & $0.918(\mathrm{Kg} / \mathrm{m3})$ & 0.915 to $0.930(\mathrm{Kg} / \mathrm{m3})$ & $0.920(\mathrm{Kg} / \mathrm{m3})$ \\
\hline 4 & Solubility & $\begin{array}{c}\text { Soluble in oily } \\
\text { substances }\end{array}$ & $\begin{array}{c}\text { Soluble in oily } \\
\text { substances }\end{array}$ & $\begin{array}{c}\text { Soluble in oily } \\
\text { substances }\end{array}$ \\
\hline 5 & pH & 7.4 & 6.9 & 7.2 \\
\hline 6 & Acid value & 2.5806 & 6.2 & 4.81 \\
\hline
\end{tabular}

Table 4: Determination of SPF values

\begin{tabular}{|c|c|c|c|c|c|}
\hline S. No & Wave length & EE value & Carrot seed oil & Blue berry seed oil & Combination of both oils \\
\hline 1 & 290 & 0.015 & 0.0848 & 0.0423 & 0.0723 \\
\hline 2 & 295 & 0.0817 & 0.1837 & 0.1212 & 0.2437 \\
\hline 3 & 300 & 0.2874 & 0.2992 & 0.2318 & 0.2398 \\
\hline 4 & 305 & 0.3278 & 0.3755 & 0.3122 & 0.3925 \\
\hline 5 & 310 & 0.1864 & 0.2412 & 0.2014 & 0.2721 \\
\hline 6 & 315 & 0.0837 & 0.1359 & 0.0948 & 0.1213 \\
\hline 7 & 320 & 0.018 & 0.0551 & 0.0315 & 0.0621 \\
\hline \multicolumn{7}{|r|}{ Sun protection factor } & 27.78 & 21.65 & 28.90 \\
\hline
\end{tabular}




\section{CONCLUSION}

From the results obtained in the study it can be concluded that carrot seed oil, blue berry seed oil, aloevera sunscreen have significant UV absorbing property. It also helps in protection from Ultra Violet radiation. Considering the patients suffering from skin diseases and adverse effects associated with synthetic sunscreens it is the best option to use herbal sunscreens without fail. Herbal sunscreens are more safe and efficacious than synthetic sunscreens and also cost effective. Carrot seed oil and blue berry oils are selected because of their good SPF values. Aloe vera is having numerous advantages related to skin. Niosomal formulation is prepared to enhance the absorption ability of sunscreen.

\section{ACKNOWLEDGEMENT}

We are grateful to the management and principal of Chalapathi Institute of Pharmaceutical Sciences, Guntur who have provided all the necessary eminities to carry out the research work.

\section{REFERENCES}

[1] Silvia Tampucci, Susi Burgalassi et al., Cutaneous Permeation and Penetration of Sunscreens: Formulation Strategies and In Vitro Methods; Cosmetics; Dec. 2017, 5(1).
[2] Mukund Manikrao Donglikar and Sharada Laxman Deore., Development and Evaluation of Herbal Sunscreen. Pharmacogn J. 2017; 9(1): 83-97.

[3] Gies PH, Roy CR, Toomey S, McLennan A. Protection against solar ultraviolet radiation. Mutation Research. 1998; 422(1): 15-22.

[4] Goswami PK et al., Aloevera, Sch. Acad. J. Pharm., 2013; 2(6): 458-463.

[5] Abdulrasheed A, Aroke U.O. Parametric Studies of Carrot Seed Oil Extract for the Production of Medicated Soap.

[6] https://www.gracefruit.com/uploa ds/attachments/product/1056/blue berry-seed-oil-cofa-lotKMO1073.pdf.

[7] Manikrao Donglikar, M.; Laxman Deore, S. Sunscreens: A review. Pharmacogn. J. 2016, 8, 171-179.

[8] Vaishali Bambal, Neha Wyawahare, et al. Study of sunscreen activity of herbal cream containing flower extract of Nyctanthes arbortristis and Tagetes erecta L. International Journal of Pharmaceutical 
Sciences Review and Research.

2011; 11(1): 142-146.

[9] Pachpawar, U N Mahajan et al., Formulation and evaluation of sun protective topical preparation; International research journal of pharmacy. 2017; 12(5).

[10] Dromgoole SH and Maibach HI. Sunscreening agent intolerance: contact and photo contact sensitization and contact urticaria. J. Am. Acad Dermatol. Jun 1990; 22(6): 1068-78.

[11]W. D. Ratnasooriya, R. N. Pathirana et al., Evaluation of in vitro sun screen activities of salt marshy plants Suaeda monoica, Suaeda maritima and Halosarcia indica, International Journal of Pharmaceutical Research \& Allied Sciences, 2016, 5(2):1520.

[12]M. Patel, Sunil K. Jain et al., Preparation and Characterization of Oxybenzone-Loaded Gelatin Microspheres for Enhancement of Sunscreening Efficacy, 2006.

[13] Piergiacomo buso, Matteo radice et al., Guidelines for the development of herbal based sunscreen. Research gate, Dec 2017.
[14]Gies PH, Roy CR, Toomey S, McLennan A. Protection against solar ultraviolet radiation. Mutation Research. 1998; 422(1): 15-22.

[15]Didem Ag Seleci, Muharrem Seleci, et al. Niosomes as Nanoparticular Drug Carriers: Fundamentals and Recent Applications. Journal of Nanomaterials. 2016; 5(1).

[16] Saniega Prianni, Kiki Ayu Mela, et al., Development sunscreen Microemulsion Gel containing nhexane fraction of Mangosteen pericarp (Garcinia mangostana Linn.). Research journal of Pharmaceutical, Biological and Chemical Sciences; 2014.

[17]Monti， D.; Tampucci, S.; Chetoni, P.; Burgalassi, S.; Saino, V.; Centini, M.; Staltari, L.; Anselmi, C. Permeation and distribution of ferulic acid and its cyclodextrin complex from different formulations in hairless rat skin. AAPS PharmSciTech., 2011, 12, 514-520.

[18]Beach Hao Ou-Yang, and Richard Bradley Rzendzian; Article Sunburn Protection by Sunscreen Sprays, 16 February 2017. 
[19] Le Thi Nhu Ngoc, Vinh Van Tran, Ju-Young Moon., Recent Trends of Sunscreen Cosmetic: An Update Review; Cosmetics 2019, 6(4), 64.

[20]Palm, M.D, O’ Donoghue, M.N. Update on photoprotection. Dermatol. Ther. 2007，20, 360-376. 25. Curr. Opin. Pharmacol. 2019, 46, 24-28.

[21]Deepak M. Kasote, Surendra S. Katyare; Significance of Antioxidant Potential of Plants and its Relevance to Therapeutic Applications; International J. of biological sciences; 2015; 11(8): 982-991.

[22] Shahlla Imam, Iqbal Azhar., Invitro evaluation of sun protection factor of a cream formulation prepared from extracts of Musa accuminata (L.), Psidium gujava (1.) and Pyrus communis (1.) Asian J. pharmaceutical and clinical research. Mar. 2015. 